OPEN ACCESS

Edited by:

Marco Bani,

University of Milano Bicocca, Italy

Reviewed by:

Shamshad Khan,

University of Texas at San Antonio,

United States

Rano Mal Piryani,

Liaquat University of Medical and Health Sciences, Pakistan Jianbiao Li,

Nankai University, China

*Correspondence: Jennie Haw

jennie.haw@blood.ca

Specialty section:

This article was submitted to Health Communication,

a section of the journal

Frontiers in Communication

Received: 15 September 2021 Accepted: 14 December 2021 Published: 17 January 2022

Citation:

Haw J, Thorpe $R$ and Holloway K (2022) Blood Collection Agency Messaging to Donors and the Public in Canada and Australia During the Early

Days of COVID-19.

Front. Commun. 6:777829. doi: 10.3389/fcomm.2021.777829

\section{Blood Collection Agency Messaging to Donors and the Public in Canada and Australia During the Early Days of COVID-19}

\author{
Jennie Haw ${ }^{1,2 *}$, Rachel Thorpe ${ }^{3,4}$ and Kelly Holloway ${ }^{5,6}$ \\ ${ }^{1}$ Donation Policy and Studies, Canadian Blood Services, Ottawa, ON, Canada, ${ }^{2}$ Department of Health Sciences, Carleton \\ University, Ottawa, ON, Canada, ${ }^{3}$ Clinical Services and Research, Australian Red Cross Lifeblood, Melbourne, VIC, Australia, \\ ${ }^{4}$ Centre for Health Equity, Melbourne School of Population and Global Health, The University of Melbourne, Carlton, VIC, Australia, \\ ${ }^{5}$ Donation Policy and Studies, Canadian Blood Services, Toronto, ON, Canada, ${ }^{6}$ Management, and Evaluation, Institute of Health \\ Policy, University of Toronto, Toronto, ON, Canada
}

COVID-19 has posed unprecedented challenges to health systems around the world, including blood collection agencies (BCAs). Many countries, such as Canada and Australia, that rely on non-remunerated voluntary donors saw an initial drop in donors in the early days of the pandemic followed by a return to sufficient levels of the blood supply. BCA messaging plays a key role in communicating the needs of the blood operator, promoting and encouraging donation, educating, and connecting with the public and donors. This paper is an interpretive discourse analysis of BCA messaging in Canada and Australia from March 1-July 31, 2020 to understand how BCAs constructed donation to encourage donation during this period and what this can tell us about public trust and blood operators. Drawing on multiple sources of online content and print media, our analysis identified four dominant messages during the study period: 1) blood donation is safe; 2) blood donation is designated an essential activity; 3) blood is needed; and 4) blood donation is a response to the pandemic. In Canada and Australia, our analysis suggests that: 1) in a time of uncertainty, donors and some publics trusted the $\mathrm{BCA}$ to be an organization with expertise to ensure that donation is safe, essential, and able to meet patient needs; and 2) BCAs demonstrated their trustworthiness by aligning their messaging with public health and scientific experts. For BCAs, our analysis supports donor communications that are transparent and responsive to public concerns and the local context to support public trust. Beyond BCAs, health organizations and leaders cannot underestimate the importance of building and maintaining public trust as countries continue to struggle with containment of the virus and encourage vaccine uptake.

Keywords: blood donation, blood collection agency, public trust, COVID-19, messaging, discourse analysis

\section{INTRODUCTION}

On March 11, 2020, the WHO declared COVID-19 a global pandemic posing unprecedented challenges to health, social, and economic systems around the world. Since then, some blood collection agencies (BCAs) worldwide have experienced challenges in maintaining adequate blood supplies, reporting decreases in donations of up to $30 \%$ in some areas early in the pandemic 
(Gammon et al., 2021; Leung and Lee, 2020; Loua et al., 2021; Silva-Malta et al., 1111; Stanworth et al., 2020). Many countries responded to concerns about the impact of the pandemic on blood supplies by implementing measures to reduce the demand for blood, such as cancelling elective surgery (Stanworth et al., 2020), while BCAs issued call outs for donors (Mohammadi et al., 2020). Studies have reported that these measures successfully mitigated shortages in the short-term, however the problem of maintaining the blood supply in these unprecedented circumstances is a long-term one, given the longevity and unique features of this pandemic, and ongoing demand for blood for procedures that require transfusion (Nieto-Calvache et al., 2020). During previous national crises, such as $9 / 11$ in the United States and bushfires in Australia, donors and non-donors have been shown to respond positively to calls to donate blood (Glynn et al., 2003; Tran et al., 2010; Spekman et al., 2021). However, during COVID-19 social distancing measures and government lockdowns have limited people's movement and mobility and the ability of BCAs to hold mobile collection events. Beyond the logistical challenges of following public health guidelines, maintaining physical distancing and limiting the numbers of people that can congregate, BCAs must also respond to the social and psychological concerns of donors, the general public, and staff during these times of uncertainty and increased anxiety (Haw et al., 2020; Stanworth et al., 2020). In the early days of the pandemic, many BCAs also started collecting convalescent plasma and faced challenges encouraging donors to come forward for this purpose (Gehrie et al., 2020). Despite these challenges, in Australia and Canada, following initial increases in donor cancellations, blood supply has maintained sufficient levels suggesting strong public and donor response (Dawkins, 2020; Tomazin, 2020).

BCAs are embedded within health, regulatory, and administrative structures that shape blood collection systems, including who and how they recruit and how blood is collected. They operate within specific historical, political, and sociocultural contexts which influence their messaging and rhetorical strategies and the sociocultural scripts that underlie these messages (Charbonneau and Smith, 2015). The messages have to "make sense" to the public in order for them to respond to the call for donations. Moreover, blood donation is a social practice that requires not only individual resources and personal motivations but is shaped by institutional and sociocultural factors that influence who is able to donate and why they donate (Piliavin et al., 1991; Healy, 2006; Charbonneau and Smith, 2015). For example, sociologists have argued that notions of individual altruism as motivating donation must be understood in the context of organizational opportunities (Healy, 2000).

BCA messaging plays a key role in communicating the needs of the blood operator, promoting and encouraging donation, educating, and connecting with publics and donors. To be effective, BCA messages must draw on sociocultural scripts regarding blood donation that make sense and are understandable to the communities and publics that they aim to reach (Healy, 2000; Raivola, 2020). Moreover, messaging plays a role in shaping, constructing, and re-constructing these scripts that aim to communicate a shared, and perhaps aspirational, understanding of the relations between the blood operator, donors, and patients. Through these scripts, messaging communicates ideas about roles, responsibilities, expectations, and commitments between these various social actors. In many western countries, including Canada and Australia, trust is a key component in the relationship between BCAs and donors and underlies sociocultural scripts on blood donation (Raivola, 2020). Beyond its importance in ensuring sufficiency of the blood supply during COVID-19, public trust in health organizations and leaders is increasingly recognized as critical to encouraging adherence to public health recommendations, including vaccine uptake (Goldenberg, 2021).

This paper is an interpretive discourse analysis of Canadian Blood Services' (CBS) and Lifeblood's messaging to donors and the public during the early days of the COVID-19 pandemic. To our knowledge, no research has examined BCA messaging during a pandemic. Moreover, no analysis has considered how BCAs construct donation during a national crisis and what this can tell us about public trust and blood operators. The guiding questions in our analysis were: How do CBS and Lifeblood construct blood donation in their messaging to the public and donors? What can the messaging tell us about the trust between BCAs and donors in the context of a pandemic?

\section{BACKGROUND}

To contain and suppress the spread of COVID-19, public health officials in most jurisdictions were recommending, and in some cases requiring, the public to alter their behaviour by minimizing going out and in-person contact, maintaining physical distance, wearing a mask, and hand washing frequently. While research conducted early in the pandemic demonstrated public support for these measures, data also suggest that increased public health messaging may lead to greater anxiety for some (Barari et al., 2020). Approaches to public health messaging must also be mindful of "information overload" and the limits of information to change behaviours (Barari et al., 2020). Consistency of public health messaging during COVID-19 has also been a challenge in many jurisdictions, which is concerning given the importance of public trust in encouraging behavioural compliance (Cairns et al., 2013). In Canada, qualitative analysis of messaging from provincial chief medical officers of health found that messages were similar across provinces in the early days of the pandemic but diverged over time (Fafard et al., 2020). However, the authors argue that the lack of consistency in messaging across all the provinces was not necessarily a problem since they were taking into account the specific conditions in their province. Analysis of government messaging in Australia also found inconsistencies between federal and state government advice (Rajkhowa, 2020). Qualitative analysis of COVID-19 information sources in Australia demonstrates that people consider some sources of COVID-19 information more trustworthy than others; however, expressed a high degree of trust in the advice of government and public health, as well as others considered to have expert knowledge, such as healthcare professionals (Lupton and Lewis, 2021). 
Blood operators in countries that rely on voluntary nonremunerated (VNR) donors focus on risk mitigation and ensuring safety with an aim to build and maintain a trust relationship between donors, recipients and the blood operator (Farrell, 2006; Brailsford et al., 2015; Wittock et al., 2019). Research with donors in these countries has found that regular donors demonstrate high levels of trust in blood operators due to organizational reputation and history, and because of positive interactions with blood collection staff (Wynne Busby, 2010; Raivola et al., 2019). However, the trust relationship between BCAs and the public is dynamic and must be continuously negotiated and re-negotiated according to changing conditions (Charbonneau and Quéniart, 2015; Charbonneau and Smith, 2015). The COVID-19 pandemic has, no doubt, altered conditions of donation and introduced new safety concerns not only to the recipient, but also to the donor. While survey research with donors during prior viral outbreaks suggest that fear has a negative impact on willingness to donate (Shan and Zhang, 2004; Masser et al., 2011), a study conducted during the current pandemic found that donors' and prospective donors' perceived risk of infection did not necessarily deter them from donating (Masser et al., 2020). Researchers found that trust in the blood organization was key to informing survey participants' beliefs about donating during the pandemic. Participants' perceived risk comprised one component of the perceived costs of donating, which was balanced by their perception of the positives of donating and confidence to donate during the pandemic (Masser et al., 2020). As such, Masser et al. (2020) recommend that blood operators use communications to build and maintain trust with donors. This is consistent with research that demonstrates that the effectiveness of messaging to encourage particular behaviours, both from public health sources and BCAs, depends on maintaining public trust (Smith et al., 2011; Henderson et al., 2020; Udow-Phillips and Lantz, 2020). In the context of the COVID-19 pandemic, the potential for disruption or destabilization of the trust relationship between donors and BCAs is heightened given the uncertainty and continuous changes. The potential fallout of decreased trust may be even more detrimental if BCAs must recruit large numbers of new donors who may not be familiar with the organization during a crisis.

While public and donor trust in BCAs has been demonstrated to be an important factor in encouraging blood donation, there has been little work on theorizing trust in donation literature whether for clinical or research purposes (Sheikh and Hoeyer, 2018). Beyond donation literature, scholars have conceptualized trust in a number of ways (Sheikh and Hoeyer, 2018). For this paper, we consider two related understandings of trust. First, a sociological perspective on trust that moves beyond conceptualizations of what trust is to what it can enable or make happen. As Luhmann (1999) argued, "trust is the name for a shortcut to social action that we need when we operate in contexts we cannot fully know or scrutinize." (cited in Sheikh and Hoeyer 2018: 170). In the early days of the pandemic, when there was great uncertainty, people in Canada and Australia continued to engage in the social act of donation. This, in addition to research indicating self-reports of trust in the BCA (Masser et al., 2020), suggest that trust was operating to enable donation. It is reasonable to assume that BCA messaging played some role in mobilizing trust. Second, scholars examining public trust in science have suggested moving from trust to trustworthiness (Aitken et al., 2016). Doing so shifts focus from the publics involved (e.g., why some groups lack trust in science) to the research and researchers (e.g., what makes research/researchers trustworthy). On this view, BCAs occupy an analogous position to research/researchers, and the messages they produce are one way to communicate to donors and the public that they are trustworthy. Taking an interpretivist approach, we do not aim to assess or measure messaging with levels of trust in donors and the public, but rather to explore what BCA messaging might tell us about trust and blood operators' trustworthiness.

Given their similarities and differences, Canada and Australia offer interesting case studies of BCA messaging in two jurisdictions during the early days of the COVID-19 pandemic. Both countries have centralized national blood operators (Canadian Blood Services0F1 and Australian Red Cross Lifeblood), rely on voluntary non-remunerated blood donors, have publicly funded healthcare systems, and both are Commonwealth Nations with similar political systems. BCAs in both countries are part of international blood organizations that share knowledge and information and have been in close communication throughout the pandemic. Canada and Australia, however, differ in their location and geography, and the epidemiology and spread of COVID-19. As an island nation, Australia was able to more effectively close its borders and keep the numbers of positive cases low. Still, from mid-March to early April, both countries enacted various measures including: issuing travel advisories; closing borders, closing schools, public facilities, and non-essential businesses; requiring self-isolation and quarantine measures; and issuing stay-at-home orders. By late April/early May, both countries started to loosen restrictions. In addition, Australia entered 2020 in the midst of an unprecedented bushfire crisis prompting a national call out for blood donors in early January which meant donors responding to this call were not eligible to donate in March, at the start of the pandemic, given the mandatory minimum wait period between donations. In Canada, by July 31,2020 (the end of the study period), the prevalence rate of COVID-19 cases was 309/100,000 and the death rate was 24/100,000.1F2 In Australia, over the same period, the prevalence rate was $66 / 100,000$ and death rate was $0.8 /$ $100,000 . .^{1,2,3,4}$

\footnotetext{
${ }^{1}$ Canadian Blood Services is the national blood operator for all provinces and territories in Canada except Quebec

${ }^{2}$ https://news.google.com/covid19/map?hl=en-CA\&mid= $\% 2 \mathrm{Fm} \%$ 2F0d060g\&gl=CA\&ceid=CA\%3Aen, downloaded March 4, 2021 ${ }^{3}$ https://www.health.gov.au/sites/default/files/documents/2020/08/coronaviruscovid-19-at-a-glance-31-july-2020.pdf, downloaded March 19, 2021. ${ }^{4}$ https://www.publicsafety.gc.ca/cnt/ntnl-scrt/crtcl-nfrstrctr/esf-sfe-en.aspx, downloaded March 8, 2021
} 
TABLE 1 | Covid-19 public health and government responses in Australia and Canada.

\begin{tabular}{|c|c|c|c|c|}
\hline Event & Date & Australia & Date & Canada \\
\hline First COVID-19 case & 29 Jan & First case confirmed in Australia & 25 Jan & First case confirmed in Canada \\
\hline Travel restrictions & 01 Mar & $\begin{array}{l}\text { Travel restrictions and self-isolation measures } \\
\text { introduced for people returning from international travel }\end{array}$ & 05 Mar & $\begin{array}{l}\text { Provinces begin implementing mandatory 14-days } \\
\text { self-isolation for those returning from international } \\
\text { travel }\end{array}$ \\
\hline \multicolumn{5}{|c|}{11 March - WHO declares covid-19 a pandemic } \\
\hline Travel restrictions & 15 Mar & $\begin{array}{l}\text { The Australian Federal Government introduces a ban } \\
\text { on all international travel }\end{array}$ & 14 Mar & $\begin{array}{l}\text { Government of Canada issues travel advisory } \\
\text { warning against all non-essential travel outside } \\
\text { Canada }\end{array}$ \\
\hline Border restrictions & 20 Mar & $\begin{array}{l}\text { Travel restrictions: Only Australian citizens, residents } \\
\text { and immediate family members can travel to Australia }\end{array}$ & 18 Mar & $\begin{array}{l}\text { Travel restrictions on entry of all foreign nationals } \\
\text { (except from US); extended to US foreign nationals } \\
\text { (21 Mar) }\end{array}$ \\
\hline $\begin{array}{l}\text { Elective surgeries } \\
\text { suspended }\end{array}$ & 24 Mar & Temporary suspension of elective surgery 24 March & 15-23 Mar & $\begin{array}{l}\text { Most provinces and territories in Canada suspend } \\
\text { non-urgent surgeries and medical services }\end{array}$ \\
\hline- & - & - & 16 Mar & $\begin{array}{l}\text { Canada's Chief Public Health Officer, Dr. Theresa } \\
\text { Tam, makes a public statement that blood donation } \\
\text { is essential and encourages Canadians to continue } \\
\text { to donate }\end{array}$ \\
\hline- & - & - & 19 Mar & $\begin{array}{l}\text { Canada's Prime Minister, Justin Trudeau, } \\
\text { encourages Canadians to continue to donate blood }\end{array}$ \\
\hline $\begin{array}{l}\text { Service and social } \\
\text { restrictions introduced }\end{array}$ & $23 \mathrm{Mar}$ & $\begin{array}{l}\text { Stage } 1 \text { restrictions introduced: restrictions on services } \\
\text { allowed to open, gatherings, social distancing } \\
\text { recommended, avoid non-essential travel }\end{array}$ & 14-21 Mar & $\begin{array}{l}\text { Various levels of government enact measures to } \\
\text { close schools, public facilities, non-essential } \\
\text { businesses, and place limits on the number of people } \\
\text { who can gather indoors and outdoors. Work-from- } \\
\text { home guidelines are established. The public is } \\
\text { encouraged to maintain physical distance, limit social } \\
\text { gatherings, and go out for essential activities only }\end{array}$ \\
\hline $\begin{array}{l}\text { Service and social } \\
\text { restrictions tightened }\end{array}$ & 25 Mar & $\begin{array}{l}\text { Stage } 2 \text { restrictions introduced: tighter service and } \\
\text { social restrictions }\end{array}$ & - & - \\
\hline $\begin{array}{l}\text { Service and social } \\
\text { restrictions tightened }\end{array}$ & 30 Mar & $\begin{array}{l}\text { Stage } 3 \text { restrictions introduced: tighter service and } \\
\text { social restrictions - non-essential venues closed; limits } \\
\text { on leaving home except for essential reasons; } \\
\text { gatherings limited to no more than two people }\end{array}$ & - & - \\
\hline $\begin{array}{l}\text { Reintroduction of some } \\
\text { elective surgeries }\end{array}$ & $27 \mathrm{Apr}$ & Re-introduction of some elective surgeries from & 01-26 May & $\begin{array}{l}\text { Most provinces and territories in Canada resume } \\
\text { non-urgent surgeries and medical services }\end{array}$ \\
\hline $\begin{array}{l}\text { Easing of service and } \\
\text { social restrictions }\end{array}$ & 28 Apr & $\begin{array}{l}\text { Some states and territories begin easing service and } \\
\text { social restrictions }\end{array}$ & $\begin{array}{l}\text { Early } \\
\text { May-late Jul }\end{array}$ & $\begin{array}{l}\text { Staged easing of Covid-19 restrictions in all } \\
\text { provinces and territories in Canada }\end{array}$ \\
\hline $\begin{array}{l}\text { Re-introduction of service } \\
\text { and social restrictions }\end{array}$ & 30 Jun & $\begin{array}{l}\text { State of Victoria introduces stronger restrictions } \\
\text { following start of second wave of infections }\end{array}$ & - & - \\
\hline
\end{tabular}

\section{MATERIAL AND METHODS}

\section{Methodological Approach}

This paper offers an interpretive discourse analysis of Canadian Blood Services' and Lifeblood's messaging to donors and the public in the early days of the pandemic. As scholars have pointed out, "discourse" has multiple definitions across different disciplinary fields and "discourse analysis" as a methodologic technique can take many forms ranging from more objectivist to interpretivist approaches (Buus, 2005; Bloor and Bloor, 2013). While some consider this multiplicity and lack of clarity a potential limitation of discourse analysis (Buus, 2005), others consider this flexibility as appropriate given the range of disciplinary trajectories, potential uses, and complexities of the social and linguistic domains (Bloor and Bloor, 2013). We take an interpretivist approach informed by critical discourse analysis as outlined by Bloor and Bloor (2013). They define discourse as "all the phenomena of symbolic interaction and communication between people, usually through spoken or written language or visual representation." (2013: 6). According to this approach, words and messages are both language and more than language and include the broader social and political context, the audience for the text, and social codes and meanings in its interpretive analysis (Bloor and Bloor, 2013). This analytic approach enables examination of the explicit and implicit messages to the public and donors and elucidates how the broader sociocultural context both informs and is informed by the messages. Moreover, a critical discourse analytic approach is mindful of power relations between communicator and audience and recognizes that discourse may be used by those in positions of authority, including institutions, to encourage certain behaviours and maintain social structures (Bloor and Bloor, 2013).

BCAs occupy a position of authority with regard to blood donation and its need, and their role in relation to donors and the public should be considered when evaluating their communication. BCA messaging is also intended to elicit 
TABLE 2 | Key operational changes and announcements made by Lifeblood and CBS.

\begin{tabular}{|c|c|c|c|c|}
\hline Changes & Date & Lifeblood (Australia) & Date & CBS (Canada) \\
\hline $\begin{array}{l}\text { Additional Donor screening } \\
\text { measures }\end{array}$ & $\begin{array}{l}03 \text { Mar } \\
13 \text { Mar }\end{array}$ & $\begin{array}{l}\text { 28-days deferral introduced for people returning from } \\
\text { high prevalence countries on } \\
\text { 28-days deferral extended to anyone returning from } \\
\text { international travel }\end{array}$ & $16 \mathrm{Mar}$ & $\begin{array}{l}\text { New screening measures for COVID-19 applied: anyone } \\
\text { asked by public health to place themselves under } \\
\text { observation or self-quarantine are not allowed to donate for } \\
14 \text { days from the date of their last contact with a case or } \\
\text { suspected case of COVID-19; anyone with a case or } \\
\text { suspected case in their household cannot donate for } \\
14 \text { days after the infected person's recovery; anyone with a } \\
\text { confirmed case of COVID-19 are not allowed to donate for } \\
56 \text { days after full recovery from the infection }\end{array}$ \\
\hline Key announcements & $\begin{array}{l}03 \text { Mar } \\
17 \text { Mar }\end{array}$ & $\begin{array}{l}\text { Lifeblood sends email to all active donors with an } \\
\text { update on actions taken by Lifeblood related to } \\
\text { COVID-19 } \\
\text { Lifeblood Media release calling for } 14,000 \text { donors }\end{array}$ & 19 Mar & $\begin{array}{l}\text { CBS posts a video message by CEO, Dr. Graham Sher, } \\
\text { thanking the Prime Minister and public health leaders for } \\
\text { sharing the message of the ongoing need for blood. Asks } \\
\text { the public and donors to continue to donate to sustain } \\
\text { blood inventory levels }\end{array}$ \\
\hline \multirow[t]{2}{*}{$\begin{array}{l}\text { Additional safety measures } \\
\text { in donor centres }\end{array}$} & 19 Mar & $\begin{array}{l}\text { Additional disinfecting and cleaning measures } \\
\text { introduced in donor centres }\end{array}$ & $\begin{array}{l}\text { Mid- } \\
\text { late Mar }\end{array}$ & $\begin{array}{l}\text { New enhanced cleaning measures, physical distancing, } \\
\text { and additional wellness measures implemented in donor } \\
\text { centres across the country }\end{array}$ \\
\hline & 23 Mar & $\begin{array}{l}\text { Social distancing measures introduced into donor } \\
\text { centres }\end{array}$ & & $\begin{array}{l}\text { Implemented a plan for PPEs for staff in collection sites } \\
\text { Walk-ins no longer accepted; donation by appointment } \\
\text { only }\end{array}$ \\
\hline $\begin{array}{l}\text { New advice for vulnerable } \\
\text { groups }\end{array}$ & 31 Mar & $\begin{array}{l}\text { Advice for people aged over } 70 \text { or with existing health } \\
\text { conditions not to donate }\end{array}$ & - & - \\
\hline Additional safety measures & 01 Apr & Wellness checks introduced in donor centres & 04 Apr & $\begin{array}{l}\text { Wellness checkpoints implemented at all donor centres } \\
\text { across the country }\end{array}$ \\
\hline $\begin{array}{l}\text { Collection of convalescent } \\
\text { plasma starts }\end{array}$ & 11 May & Collection of convalescent plasma starts & $29 \mathrm{Apr}$ & $\begin{array}{l}\text { CBS collects first plasma donation for CONCOR-1 clinical } \\
\text { trial }\end{array}$ \\
\hline Introduction of PPE & 11 Jul & $\begin{array}{l}\text { Face masks introduced for staff and donors in areas of } \\
\text { Melbourne }\end{array}$ & 04 May & $\begin{array}{l}\text { Face masks mandatory for all frontline staff in centres } \\
\text { across the country }\end{array}$ \\
\hline PPE use & $31 \mathrm{Jul}$ & Face masks for staff and donors in Victoria and NSW & 11 May & Face masks mandatory for all donors \\
\hline
\end{tabular}

particular desired behaviours in its audiences; namely, to encourage people to donate blood, and thereby achieve certain health and social goals. To be effective, these messages must be understood within their specific cultural context with includes the traditions, institutions, historical context, and knowledge base of the intended audiences (Bloor and Bloor, 2013). Examining BCA messaging from March 1, 2020-July 31, 2020, provides insight during the early days of the pandemic from initial announcements, to enacting restrictions, and gradual easing of restrictions following what many refer to as the "first wave" (see Tables 1 and $\mathbf{2}$ for government and BCA measures, respectively, implemented during this period).

\section{Data Sources}

Various sources of online content and print media were drawn upon to produce the dataset. To be included in the dataset, the following inclusion criteria were applied: 1) the target audience of the content or document were donors and/or the general public; 2) the content was posted or published between March 1-July 31,2020 ; and 3) there was sufficient written text to be analyzed. By 'sufficient' we refer to both the amount of text and substantive information in the text. For example, social media posts from CBS often linked to more comprehensive material online, thus we included the online material in our analysis and not the social media post itself. For Lifeblood we did include social media posts when they contained substantive messages that were not communicated by other modes. Based on these criteria and different communication materials produced by CBS and Lifeblood, the specific datasets for the two BCAs were comparable, but not identical.

For CBS, the dataset included: 1) stories and COVID-19related content on their website (https:/www.blood.ca/en/ covid19); 2) direct emails to donors and prospective donors; and 3) national print media. In addition to specific COVID-19related webpages providing information about the donation screening process during the pandemic, CBS' website features stories about donors or blood product recipients which act as an important platform to communicate with its donors and the public. From March 1, 2020-July 31, 2020, 71 stories had been posted with 57 aimed at donors and the public. National print media were also included in the dataset: The National Post, The Globe and Mail, and Toronto Star. A Factiva search was conducted using the keyword, Canadian Blood Services, from March 1-July 31, 2020. Results found 120 articles. Following deletion of duplicate articles and inclusion of articles only that mentioned Canadian Blood Services and blood or plasma donation, the final number of articles was 11.

For Lifeblood, the dataset included: 1) the COVID-19 Information page on the website (donateblood.com.au); 2) direct emails and SMS' to donors; 3) national print media; 4) social media posts; and 5) media releases. National print media included The Sydney Morning Herald and/or The Age; The Australian; The Herald Sun and/or Daily Telegraph; The Australian Financial Review. A Factiva search was conducted 
using the keyword, Australian Red Cross, from March 1-July 31, 2020. Results found 105 articles. Following deletion of duplicate articles and articles that did not mention blood or plasma donation, the final number was 14. Social media posts by Australian Red Cross Lifeblood (Facebook and Twitter) were included if these provided new content not also featured on the website.

\section{Data Analysis}

Following the compilation of the datasets (JH and $\mathrm{KH}$ for CBS, RT for Lifeblood), all authors read a representative selection of documents to become familiar with the data and to identify emergent themes. The three authors together developed a coding framework based on these emergent themes and prior categories of interest and discussed how to interpret and apply these codes to the messages in their respective countries. Applying this coding framework, $\mathrm{JH}$ and $\mathrm{KH}$ coded the same two documents independently and came together to resolve any differences in coding to ensure inter-coder consistency. Given the interpretivist approach taken for this analysis, it was appropriate to consider consistency, or comparison and discussion of code application between coders, rather than quantifying reliability between coders (Yardley, 2000; Thomas and Harden, 2008; O'Connor and Joffe, 2020). Moreover, since our analytic approach requires situating the messages within local context, we considered it methodologically appropriate for $\mathrm{JH}$ and $\mathrm{KH}$ (live and work in Canada) to code the data for CBS and RT (lives and works in Australia) to code the data for Lifeblood. Media articles were analyzed for the message sent by the BCA and not the reporter's view or opinion presented in the article. In iterative fashion, during the coding and analytic stages, authors looked to the literature to gain a better understanding of public health messaging during COVID-19 and other social science research examining donors, the public, and the pandemic. Following completion of coding, the authors met several times via videoconference to discuss key themes in relation to the pandemic context in both countries.

\section{RESULTS}

\section{Blood Donation is Safe}

For both CBS and Lifeblood, a dominant theme in their messaging throughout the period of analysis is that blood donation is safe both in terms of: 1) the safety of the blood supply, and 2) the safety of donors and staff in donor centres. Even before the WHO declared COVID-19 a global pandemic, the BCAs were actively sending the message that the virus does not pose a threat to the safety of the blood system. CBS and Lifeblood supported their claims of safety by referencing evidence and aligning themselves with scientific expertise:

"There is absolutely no evidence of transfusion transmission for COVID-19, or any other coronavirus," says Dr. Steven Drews, associate director of microbiology at Canadian Blood Services. “This family of respiratory viruses just doesn't appear to be transfusion-transmitted." (CBS, website stories, March 9).
There is no evidence that coronavirus is transmissible by blood transfusion (Lifeblood, donor email, March 3).

The blood operators moved very quickly to assure donors and the public that it is safe to donate blood and that their donor centres are safe. While the message of safety to donors has been consistent over the period analyzed, how this message has been framed evolved over the study period for both BCAs. In the very early days, immediately after government guidelines against nonessential movement and travel were issued, CBS messaging reassured donors and the public that donor centres were safe because they are a "rare setting" within the healthcare system that welcomes only healthy people. This exceptional status, coupled with implementation of new hygiene and wellness checks, would ensure donor safety:

As for social interaction at clinics, MacDonald (CBS territory manager) noted they are a rare health-care setting where only healthy people are welcome. New procedures at the door include hand sanitizer and questions for potential donors about how they feel and recent travel. (CBS, news media, March 19).

Lifeblood also referred to their donor centres as "places of wellness" and assured their donors that centres were safe since they had revised their screening to defer people who had travelled abroad in the prior 28 days from donation. In effect, their message was that new screening measures would keep the virus out:

... our strict screening process means we don't allow people who are unwell to donate blood. Our donor centres are safe places to visit and we will take all necessary steps to ensure that stays the case. (Lifeblood, donor email, March 3)

However, as community transmission of COVID-19 increased, along with evidence of asymptomatic carriers, BCA messaging stopped framing donor centres as places of wellness and shifted to emphasize the implementation of "enhanced wellness measures," including wellness checks at the door, limiting the number of donors at any one time, and heightened cleaning to ensure donor safety:

We've always had hospital-level cleaning processes, but because of the pandemic we've added even more measures to help protect you and our team (Lifeblood, donor email, March 20).

Donor centres have robust measures in place to protect donors, staff and volunteers (CBS, online stories, March 25).

Messages of enhanced safety measures suggest a more active approach by the BCAs to ensure donor safety. They were sent at a time when donors and the public were dealing with significant changes to their lives and experiencing fear and anxiety of infection (Brooks et al., 2020; Fitzpatrick et al., 2020). By assuring "protection," both organisations implicitly acknowledged the risks and fear people may be feeling and took responsibility for keeping them safe. Lifeblood followed government advice and indirectly protected donors perceived to be most vulnerable to infection by asking people aged 70 and 
over, those with compromised immune systems and some chronic medical conditions not to donate:

The only exception to this (to come out and donate) is our generous donors aged 70 and over who are still being advised to stay at home and self-isolate for their own protection (Lifeblood, Website, April 1).

As the epidemiology of COVID-19 evolved along with changing public health guidelines, the BCAs shifted their messages of safety to demonstrate responsiveness to and alignment with these changes. By doing so, the messages can be viewed as reassuring donors that BCAs can be trusted to follow public health expertise (Masser et al., 2020) and that they will take responsibility for ensuring safety in the donor centres.

\section{Blood Donation is Essential}

Authorities in both countries classified blood donation as an "essential" activity2F3 and BCAs reminded donors and the public in their messaging of this formal designation. BCAs also used the language of 'essential' to urge donors to continue to donate. In Australia, as case numbers increased in March, national and state-based restrictions on movement to prevent the spread of COVID-19 were introduced and rapidly tightened from stage 1 to stage 3 limiting the services deemed essential and allowed to remain open:

As many states prepare to limit non-essential activities, it is important to remember blood and plasma donation remains absolutely vital and is excluded from any restrictions to movement and venue restrictions (Lifeblood, Print media, website, twitter, Facebook from March 23 until early April).

Beginning mid-March, provinces and territories across Canada also enacted various closures and stay-at-home measures to contain the growing number of positive cases. In this context, CBS sent the message to donors and the public that donating blood is essential and exempt from lockdown and stayat-home orders:

... it's essential for healthy eligible donors to keep booking and honouring their appointments during the COVID19 pandemic. In provinces that have declared a state of emergency, the bans on social and recreational gatherings don't apply to blood donor centres. (CBS, online story, March 25)

The message that blood donation is essential and an essential activity speaks to how "vital" it is and to its exemption from state and public health restrictions limiting movement and activities. In the context of COVID-19, an essential designation situates blood donation within the same framing as essential healthcare and frontline services and thereby presented an opportunity for donors and the public to participate in lifesaving healthcare.

\section{Blood Donation is Needed}

From the start of the study period, both BCAs communicated the message that the need for blood continues despite lockdown measures and suspension of non-urgent surgeries and medical procedures. While the above measures would decrease the need for blood, the BCAs were quick to highlight the various procedures that continued to require a constant supply of blood:

Some hospitals have cancelled elective surgeries, but there still is a constant demand as a result of trauma from accidents and for cancer patients who need regular transfusions, (Dr. Isra) Levy (VP, Medical Affairs and Innovation) said. (CBS, news media, March 17).

Messages about the ongoing need for blood from both organizations employed metaphors of a marathon, "Let's all think of this as a marathon, not a sprint" (quote from Dr. Sher, CBS CEO, news media, March 27) suggesting that meeting the ongoing need for blood would require pacing, stamina, determination, and ongoing commitment by donors and the public.

Lifeblood also directly referenced local events, such as panic buying of toilet paper, that took place when social restrictions were first introduced to highlight the need for blood. By drawing on immediate local concerns related to COVID-19, Lifeblood made the constant need for blood understandable to a public that was reacting, and highly sensitized, to the potential scarcity of everyday products:

Blood is like milk, not toilet paper. You can't just buy a lot of it and save it for later-you need to have a regular, fresh supply for patients who need it (Lifeblood, Twitter/Facebook, March 31).

By bringing together the information about the limited shelflife of blood with the continuous, albeit volatile, need for blood during the pandemic, an implicit suggestion was that even when blood supply is sufficient it is always a temporary state. In other words, the message that the need for blood is constant may also be interpreted as the potential threat of insufficient blood is constant.

As the number of positive COVID-19 cases began to drop, hospitals across Canada resumed elective surgeries and lockdown measures eased resulting in increasing demand for blood. This was addressed in CBS messaging as they modified their message from "the need for blood is constant" to "the need for blood is rising." The BCA situated the need for blood directly within the context of the evolving epidemiology of COVID-19 and its related public health measures.

The need for blood is gradually increasing as hospitals resume procedures that were put on hold due to COVID-19. Elective surgeries will gradually ramp up across the nation in the coming weeks, while urgent surgeries continue. Dr. Jeannie Callum is seeing this transition firsthand in her role as a transfusion medicine specialist at Sunnybrook Health Sciences Centre in Toronto. (CBS, online story, May 28).

As COVID-19 numbers dropped, hospitals resumed procedures that had been put on hold and the need for blood increased. At the same time, people were increasing their activities as lockdown measures were loosened creating the possibility that as the need for blood increased, people may be busy with other activities and pay less attention to donating blood. To address this, CBS drew on the expertise of a transfusion medicine specialist in a busy urban hospital to provide a first-hand, frontline account of the rising need for blood. This shift in messaging did not occur in Australia 
during the study period. Instead messaging acknowledged the response from donors during the pandemic while also reinforcing the messages of blood donation being essential, needed and safe.

\section{Blood Donation is a Response to the Pandemic}

Unique to COVID-19 conditions, BCA messaging constructed blood donation as a response to the pandemic with slight differences in Canada and Australia. In Canada, from the early days, public health leaders recognized the toll the pandemic was taking on people's mental health given the restrictions and perceived lack of control. In a context where authorities were asking the public to limit their activities outside of the home and people were dealing with the strain resulting from the loss of social interaction, blood donation was presented as a way for people to leave their homes and exercise personal agency during challenging times. By quoting public health leaders, CBS aligned themselves with health experts and reinforced the message that blood donation was a way to respond to the negative toll the pandemic was taking on individuals:

Giving can also benefit donors, according to Dr. Deena Hinshaw, Alberta's chief medical officer of health. "Blood donation can help address the feeling of helplessness people have in the face of COVID-19," said Dr. Hinshaw in a public statement on Mar. 16, 2020. "Gaining a sense of control by helping others can contribute to an overall sense of wellbeing." (CBS, online story, March 17).

CBS also communicated the message of donation as a rare opportunity to contribute to the community under pandemic conditions through their online stories that featured donors. In these personal narratives, the pandemic was framed as eliminating the usual ways in which people contributed to their community leading some people to turn to blood donation to do something "to feel valuable and useful in the community" (CBS, online story, April 24). One donor constructed blood donation as a way to address feelings of fear associated with the pandemic:

"When faced with hard times, the church community always asks, 'what then shall we do?'” says Kevin. For him, an answer came during an address by Justin Trudeau, in which the prime minister called on Canadians to donate blood during the pandemic. "The community was afraid and focused on everything they couldn't do anymore because of the lockdown," he says. "I decided that donating blood was the one thing we could do." (CBS, online story, June 10).

Perhaps no other type of donation is more exemplary as a response to COVID-19 than donating convalescent plasma for clinical trials. The pandemic created the opportunity for a new kind of donation that both CBS and Lifeblood were responsible for collecting and administering. During the study period, both BCAs started recruiting people who had recovered from the virus to donate their plasma for use in these clinical trials. For CBS, online stories that featured convalescent plasma donors constructed donation as a response to COVID-19 by "pushing back" against the effects of the pandemic:
Patrick donated in Toronto on May 6. Like his father, it was his first donation of a blood product, and he was thrilled to donate for this purpose. "I was happy to contribute what I could," he said. "You just feel so helpless right now. I'd love to do my part to kind of push the world back to a state of normalcy." (CBS, online story, May 6).

Lifeblood also communicated messages of donating convalescent plasma to respond to the pandemic, specifically aimed at people who had recovered from the virus to help others infected by it. By helping others suffering from the illness, convalescent plasma donors were being invited to "be part of" a group of people who can help others:

Donating plasma is a simple, powerful act that could help a patient struggling to fight the disease. It's a real opportunity for people who have battled COVID-19 to become part of a potential solution (Lifeblood, Convalescent plasma webpage, May 11 onwards).

Stories of convalescent plasma donors were also featured in Lifeblood and general news media. Reflecting the messaging used by Lifeblood, donors tended to talk about donation as a way to help and as a responsibility. For example, Dean saw donating as way to help others "It's an opportunity to help those in dire need of assistance to overcome the virus" (Lifeblood, Facebook, June 11), while Max talked about donating convalescent plasma as an aspect of civic duty, "We live in a society, and we have a responsibility to help others as part of that society" (Lifeblood, Print media. July 30).

\section{DISCUSSION AND CONCLUSION}

Overall, BCA messages from March 1, 2020-July 31, 2020 were simple, clear, and consistent and constructed blood donation as safe, essential, needed, and as an opportunity to respond to the pandemic. In the context of public health and government guidelines and recommendations that many have found confusing and contradictory (Rajkhowa, 2020), the straightforward and clear messaging from the BCAs is significant and noteworthy. While we cannot claim a causative relationship between messaging and public response, we do suggest that the messaging contributed to activating donor response and eliciting the desired social behaviour. We suggest that these messages functioned to support the public's enacting of the desired social behaviour (i.e., blood donation) in a context of uncertainty. Moreover, we suggest these constructions of blood donation alongside CBS and Lifeblood's ability to maintain sufficiency of the blood supply over this period tells us the following in terms of trust and BCAs: 1) in a time of uncertainty, donors and some publics trusted the BCA to be an organization with expertise to ensure that donation is safe, essential, and able to meet patient needs; and 2) BCAs demonstrated their trustworthiness by aligning their messaging with public health and scientific experts. We discuss these points further in the remainder of the discussion.

BCA messaging that emphasized the safety of blood donation during the pandemic was both aided by the trust that the public has in CBS and Lifeblood (Masser et al., 2020) and reassured the public that the BCAs could be trusted during 
these uncertain times. As for previous pandemics, this early focus on safety was necessary given the context of the identification of a new virus with uncertain potential for transmission via transfusion (Shan and Zhang, 2004; Stanworth et al., 2020). Research shows the importance of trust in encouraging people to donate during a pandemic (Masser et al., 2020). By ensuring protection in their messaging and demonstrating safety through wellness measures in donor centres, CBS and Lifeblood acknowledged the fear felt by the public and agreed to take responsibility for the health and wellbeing of donors. By recognizing and legitimizing the concerns of donors, the BCAs were demonstrating sensitivity to the public's fears associated with the pandemic. This acknowledgement and sensitivity, coupled with accepting responsibility for ensuring safety, may contribute to stabilize the trust relationship between BCAs and donors.

Through their messaging, BCAs were inviting donors and the public to make, and renew, a shared commitment to meet patient needs. Bringing together the constructions of donation as safe, essential, and needed, we suggest Lifeblood and CBS outlined their commitment to ensure safety and asked donors to share the responsibility and commitment of the BCAs to meet patient blood needs. Inviting the public to share in $\mathrm{CBS}^{\prime}$ responsibility and commitment to meet patient needs is consistent with the blood operator's branding as "Canada's Lifeline", as it is with Lifeblood's brand "Together we're Australia's Lifeblood." Messages aligning the need for blood with citizenry and larger body politic evoke a sense of nationhood, with the donor and organization positioned as jointly working to keep the national blood supply strong even during the pandemic. In this way, the Lifeline or Lifeblood that connects donor to recipient through the constant need for blood reinforces the aspirational symbolic image of a unified national "body" that, like a physical body, requires the continuous flow of blood.

In the early days of the pandemic, there was great uncertainty, and BCAs may be viewed as demonstrating trustworthiness through their alignment with public health and scientific experts. While BCAs occupy a position of institutional authority in their role as blood operators, the novelty of COVID-19 had the potential to destabilize this authority and cause donors and the public to question whether BCAs could be trusted since knowledge about the novel virus was limited. That BCAs drew on scientific experts and other trusted leaders, such as national Public Health Officers and government leaders, communicated to donors and the public that BCAs were acting based on sound scientific evidence and trusted sources. It is worth noting that for this message to make sense to the receiver, the latter likely considers Western science and state leaders as trustworthy. That the blood systems in both countries have been successful in maintaining their supplies and meeting blood needs during the analysis period suggest that donors and the public that responded are likely to consider BCAs to be trustworthy.

For BCAs, our analysis supports donor communications that are transparent and responsive to public concerns, and the local context, to support public trust. In this context, special attention may need to be paid to those people and populations who are excluded from donation during this time when BCAs are making urgent appeals for donation. For example, research indicates that people from Black communities in North America, Australia and some European countries participate less in blood donation because of mistrust in healthcare systems given experiences of systemic racism and mistreatment (Grassineau et al., 2007; Polonsky et al., 2011; Tran et al., 2013). How the pandemic has affected specific communities in relation to blood donation, remains an important area for further research. Further limitations of our analysis include the following. First, although donors have responded, it is less clear who was able to respond to these call-outs and why, and whether there are any differences in perceptions of the risk of donation and trust in government by people in different social locations. While there appears to be a high degree of trust in the BCA among existing donors and some members of the general public, this is likely not the case for all social groups and communities. Second, both jurisdictions examined in this paper are high-income countries where public trust in government is relatively high and state officials showed strong support for public health evidence during the pandemic. While the approaches taken by these organisations was successful in these contexts, other BCAs may have to adapt messaging to the local context in order to build and maintain trust with donors and the public. Lastly, our analysis demonstrates how BCA messaging constructed blood donation; however, we are not able to claim a direct causal relationship between messaging content and donor response. Future research could address this gap.

Given the dynamic nature of the pandemic, much has changed since the period of analysis. Convalescent plasma trials in Canada and Australia have stopped since trials did not demonstrate any benefit of convalescent plasma for COVID-19 patients, and recruitment for these donations is no longer occurring. Currently, both countries are trying to manage fourth waves of infections and the highly transmissible delta variant while also trying to balance limiting activities and movement with the social and economic impacts of extended lockdown measures. Populations in both countries are showing fatigue with COVID-19 and are increasingly divided over the best way forward. Throughout all this, BCAs must continue to encourage donation to ensure blood needs are met. Our analysis suggests that messaging should attend to the specific context and concerns of donors both explicitly and implicitly, and continue to be simple, straightforward, and consistent.

Beyond BCAs, health organizations and leaders cannot underestimate the importance of building and maintaining public trust as countries continue to struggle with containment of the virus and encourage vaccine uptake. Any public health effort that requires people to interact with health professionals will be challenging during a pandemic, where public health advocates must address the tension inherent in recommendations to limit exposure by staying home, while also encouraging people to travel to a healthcare facility. This issue has come up in health promotion activities like cancer screening (Issaka and Somsouk, 2020; Smetherman, 2020; Tan and Lau, 2020), and in declining admission for medical 
emergencies like acute cardiovascular illness (Ebinger and Shah, 2020). This tension may also be a challenge as vaccines for COVID-19 are rolled out, and leaders attempt to address vaccine hesitancy (Dror et al., 2020; Kwok et al., 2021; Murphy et al., 2021) by emphasizing the need to re-focus and re-build trust in science and healthcare. In this context, insights from BCAs that have maintained a trust relationship with donors and have succeeded in bringing individuals donor centres during COVID-19 may be relevant and instructive.

\section{DATA AVAILABILITY STATEMENT}

The original contributions presented in the study are included in the article/supplementary materials, further inquiries can be directed to the corresponding author.

\section{REFERENCES}

Aitken, M., Cunningham-Burley, S., and Pagliari, C. (2016). Moving from Trust to Trustworthiness: Experiences of Public Engagement in the Scottish Health Informatics Programme. Sci. Public Pol. 43 (5), 713-723. doi:10.1093/scipol/ scv075

Barari, S., Caria, S., Davola, A., Falco, P., Fetzer, T., Fiorin, S., et al. (2020). Evaluating COVID-19 Public Health Messaging in Italy: Self-Reported Compliance and Growing Mental Health Concerns. medRxiv. doi:10.1101/ 2020.03.27.20042820

Bloor, M., and Bloor, T. (2013). The Practice of Critical Discourse Analysis: An Introduction, 1-207. doi:10.4324/9780203775660

Brailsford, S. R., Kelly, D., Kohli, H., Slowther, A., and Watkins, N. A. (2015). Who Should Donate Blood? Policy Decisions on Donor Deferral Criteria Should Protect Recipients and Be Fair to Donors. Transfus. Med 25 (4), 234-238. doi:10.1111/tme.12225

Brooks, S. K., Webster, R. K., Smith, L. E., Woodland, L., Wessely, S., Greenberg, N., et al. (2020). The Psychological Impact of Quarantine and How to Reduce it: Rapid Review of the Evidence. The Lancet 395 (10227), 912-920. doi:10.1016/ s0140-6736(20)30460-8

Buus, N. (2005). Nursing Scholars Appropriating New Methods: the Use of Discourse Analysis in Scholarly Nursing Journals 1996-2003. Nurs. Inq. 12 (1), 27-33. doi:10.1111/j.1440-1800.2005.00249.x

Cairns, G., de Andrade, M., and MacDonald, L. (2013). Reputation, Relationships, Risk Communication, and the Role of Trust in the Prevention and Control of Communicable Disease: A Review. J. Health Commun. 18 (12), 1550-1565. doi:10.1080/10810730.2013.840696

Charbonneau, J., and Quéniart, A. (2015). The Influence of Blood Collection Organizations on Blood Donation Motivations and Practices in Québec, Canada. Giving Blood: The Institutional Making of Altruism, Editor J. Charboneau and A. Smith Routledge, 109-128.

Charbonneau, J., and Smith, A. (2015). Introduction: Blood Donation and the Range of Historical and Institutional Trajectories. Giving Blood: The Institutional Making of Altruism, Editor J. Charboneau and A. Smith Routledge, 1-18. doi:10.4324/9781315689579

Dawkins, G. (2020). Gift of Life: Cdn Blood Services Puts Out Plea for Donations, COVID-19 Precautions in Place. Winnipeg Sun.

Dror, A. A., Eisenbach, N., Taiber, S., Morozov, N. G., Mizrachi, M., Zigron, A., et al. (2020). Vaccine Hesitancy: the Next challenge in the Fight against COVID-19. Eur. J. Epidemiol. 35 (8), 775-779. doi:10.1007/s10654-020-00671-y

Ebinger, J. E., and Shah, P. K. (2020). Declining Admissions for Acute Cardiovascular Illness. J. Am. Coll. Cardiol. 76 (3), 289-291. doi:10.1016/ j.jacc.2020.05.039

Fafard, P., Wilson, L. A., Cassola, A., and Hoffman, S. J. (2020). Communication about COVID-19 from Canadian Provincial Chief Medical Officers of Health: a Qualitative Study. cmajo 8 (3), E560-E567. doi:10.9778/cmajo.20200110

\section{AUTHOR CONTRIBUTIONS}

All authors listed have made a substantial, direct, and intellectual contribution to the work and approved it for publication.

\section{ACKNOWLEDGMENTS}

RT would like to thank Sarah Kruse, Lilly Nguyen, Barbara Masser, Erin Lagoudakis, Perfecto Diaz, Gordon Holland and Jeff Rule for assistance with gathering messaging data and timelines, providing donor behaviour data, and insights into organisational responses during the pandemic. $\mathrm{JH}$ and $\mathrm{KH}$ would like to thank members of the Communications and Marketing teams for their assistance with providing contextual insights into CBS response during the period of study.

Farrell, A.-M. (2006). Is the Gift Still Good? Examining the Politics and Regulation of Blood Safety in the European Union. Med. L. Rev. 14 (2), 155-179. doi:10.1093/medlaw/fwl001

Fitzpatrick, K. M., Harris, C., and Drawve, G. (2020). Fear of COVID-19 and the Mental Health Consequences in America. Psychol. Trauma Theor. Res. Pract. Pol. 12 (S1), S17-s21. doi:10.1037/tra0000924

Gammon, R. R., Prichard, A. B., Gannett, M. S., and Yordanov, B. (2021). The Effect of COVID-19 on Blood Donation Habits. Transfusion 61 (4), 1134-1140.

Gehrie, E. A., Frank, S. M., and Goobie, S. M. (2020). Balancing Supply and Demand for Blood during the COVID-19 Pandemic. Anesthesiology 133 (1), 16-18. doi:10.1097/aln.0000000000003341

Glynn, S. A., Busch, M. P., Schreiber, G. B., Murphy, E. L., Wright, D. J., Tu, Y., et al. (2003). Effect of a National Disaster on Blood Supply and Safety. Jama 289 (17), 2246-2253. doi:10.1001/jama.289.17.2246

Goldenberg, M. J. (2021). Vaccine Hesitancy Public Trust, Expertise, and the War on Science. University of Pittsburgh Press.

Grassineau, D., Papa, K., Ducourneau, A., Duboz, P., Boëtsch, G., and Chiaroni, J. (2007). Improving Minority Blood Donation: Anthropologic Approach in a Migrant Community. Transfusion 47 (3), 402-409. doi:10.1111/j.1537-2995.2007.01130.x

Haw, J., Holloway, K., Masser, B. M., Merz, E. M., and Thorpe, R. (2020). Blood Donation and the Global COVID-19 Pandemic: Areas for Social Science Research. Vox Sang 116 (4), 363-365. doi:10.1111/vox.12974

Healy, K. (2000). Embedded Altruism: Blood Collection Regimes and the European Union's Donor Population. Am. J. Sociol. 105 (6), 1633-1657. doi:10.1086/ 210468

Healy, K. (2006). Last Best Gifts: Altruism and the Market for Human Blood and Organs. Chicago: University of Chicago Press.

Henderson, J., Ward, P. R., Tonkin, E., Meyer, S. B., Pillen, H., McCullum, D., et al. (2020). Developing and Maintaining Public Trust during and Post-COVID-19: Can We Apply a Model Developed for Responding to Food Scares. Front. Public Health 8, 369. doi:10.3389/fpubh.2020.00369

Issaka, R. B., and Somsouk, M. (2020). Colorectal Cancer Screening and Prevention in the COVID-19 Era. JAMA Health Forum 1 (5), e200588-e. doi:10.1001/ jamahealthforum.2020.0588

Kwok, K. O., Li, K.-K., Wei, W. I., Tang, A., Wong, S. Y. S., and Lee, S. S. (2021). Influenza Vaccine Uptake, COVID-19 Vaccination Intention and Vaccine Hesitancy Among Nurses: A Survey. Int. J. Nurs. Stud. 114, 103854. doi:10.1016/j.ijnurstu.2020.103854

Leung, J. N. S., and Lee, C.-K. (2020). Impact of the COVID -19 - a Regional Blood centre's Perspective. Voxs 15 (4), 362-364. doi:10.1111/voxs.12558

Loua, A., Kasilo, O. M. J., Nikiema, J. B., Sougou, A. S., Kniazkov, S., and Annan, E. A. (2021). Impact of the COVID-19 Pandemic on Blood Supply and Demand in the WHO African Region. Vox Sang 116 (7), 774-784. doi:10.1111/vox.13071

Lupton, D., and Lewis, S. (2021). Learning about COVID-19: a Qualitative Interview Study of Australians' Use of Information Sources. BMC Public Health 21. doi:10.1186/s12889-021-10743-7 
Masser, B. M., Hyde, M. K., and Ferguson, E. (2020). Exploring Predictors of Australian Community Members' Blood Donation Intentions and Blood Donation-Related Behavior during the COVID -19 Pandemic. Transfusion 60 (12), 2907-2917. doi:10.1111/trf.16067

Masser, B. M., White, K. M., Hamilton, K., and McKimmie, B. M. (2011). An Examination of the Predictors of Blood Donors' Intentions to Donate during Two Phases of an Avian Influenza Outbreak. Transfusion 51 (3), 548-557. doi:10.1111/j.1537-2995.2010.02887.x

Mohammadi, S., Tabatabaei Yazdi, S. M., Eshghi, P., and Norooznezhad, A. H. (2020). Coronavirus Disease 2019 (COVID-19) and Decrease in Blood Donation: Experience of Iranian Blood Transfusion Organization (IBTO). Vox Sang 115 (7), 595-596. doi:10.1111/vox.12930

Murphy, J., Vallières, F., Bentall, R. P., Shevlin, M., McBride, O., Hartman, T. K., et al. (2021). Psychological Characteristics Associated with COVID-19 Vaccine Hesitancy and Resistance in Ireland and the United Kingdom. Nat. Commun. 12 (1), 29. doi:10.1038/s41467-020-20226-9

Nieto-Calvache, A. J., Quintero-Santacruz, M., Macia-Mejía, C., López-Girón, M. C., Vergara-Galliadi, L. M., and Ariza, F. (2020). Dangerous Shortage of Blood banks as an Indirect Effect of SARS-CoV-2: An Obstetrics Perspective. Int. J. Gynaecol. Obstet. 151 (3), 424-430. doi:10.1002/ijgo.13409

O'Connor, C., and Joffe, H. (2020). Intercoder Reliability in Qualitative Research: Debates and Practical Guidelines. Int. J. Qual. Methods 19, 1609406919899220. doi: $10.1177 / 1609406919899220$

Piliavin, J. A., and Callero, P. L. (1991). "Blood Donation, Social Structure and the Influence of Social Norms," in Giving Blood: The Development of an Altruistic Identity. Editor JAPAPL Callero (Baltimore and London: The Johns Hopkins Press), 179.

Polonsky, M. J., Brijnath, B., and Renzaho, A. M. N. (2011). "They Don't Want Our Blood": Social Inclusion and Blood Donation Among African Migrants in Australia. Soc. Sci. Med. 73 (2), 336-342. doi:10.1016/j.socscimed.2011.05.030

Raivola, V., Snell, K., Helén, I., and Partanen, J. (2019). Attitudes of Blood Donors to Their Sample and Data Donation for Biobanking. Eur. J. Hum. Genet. 27 (11), 1659-1667. doi:10.1038/s41431-019-0434-1

Raivola, V. (2020). The Gift of Life - Does it Apply to Donation for Research. Voxs 15 (1), 11-18. doi:10.1111/voxs.12533

Rajkhowa, A. (2020). COVID-19 Dissensus in Australia: Negotiating Uncertainty in Public Health Communication and media Commentary on a Novel Pandemic. Pac. Journalism Rev. : Te Koakoa 26 (1), 253-263. doi:10.24135/ pjr.v26i1.1091

Shan, H., and Zhang, P. (2004). Viral Attacks on the Blood Supply: the Impact of Severe Acute Respiratory Syndrome in Beijing. Transfusion 44 (4), 467-469. doi:10.1111/j.0041-1132.2004.04401.x

Sheikh, Z., and Hoeyer, K. (2018). "That Is Why I Have Trust": Unpacking what 'trust' Means to Participants in International Genetic Research in Pakistan and Denmark. Med. Health Care Philos. 21 (2), 169-179. doi:10.1007/s11019-017-9795-9

Silva-Malta, M. C. F., Rodrigues, Dd. O. W., Chaves, D. G., Magalhães, N. N. S., Ribeiro, M. A., Cioffi, J. G. M., et al. Impact of COVID-19 in the Attendance of Blood Donors and Production on a Brazilian Blood Centres. Transfus. Med. 31 (3), 206-212. doi:10.1111/tme.12733

Smetherman, D. H. (2020). Breast Cancer Screening and the COVID-19 Pandemic. J. Breast Imaging 3 (1), 3-11. doi:10.1093/jbi/wbaa106

Smith, A., Fiddler, J., Walby, K., and Hier, S. (2011). Blood Donation and Institutional Trust: Risk, Policy Rhetoric, and the Men Who Have Sex with Men Lifetime Deferral Policy in Canada. Can. Rev. Sociology/Revue canadienne de sociologie 48 (4), 369-389. doi:10.1111/j.1755-618x.2011.01269.x
Spekman, M. L. C., Ramondt, S., Quee, F. A., Prinsze, F. J., Huis in 't Veld Emj,van den Hurk, K., et al. (2021). New Blood Donors in Times of Crisis: Increased Donation Willingness, Particularly Among People at High Risk for Attracting SARS-CoV-2. Transfusion 61 (6), 1822-1829. doi:10.1111/trf.16334

Stanworth, S. J., New, H. V., Apelseth, T. O., Brunskill, S., Cardigan, R., Doree, C., et al. (2020). Effects of the COVID-19 Pandemic on Supply and Use of Blood for Transfusion. Lancet Haematol. 7 (10), e756-e764. doi:10.1016/s2352-3026(20) 30186-1

Tan, K.-K., and Lau, J. (2020). Cessation of Cancer Screening: An Unseen Cost of the COVID-19 Pandemic. Eur. J. Surg. Oncol. 46 (11), 2154-2155. doi:10.1016/ j.ejso.2020.05.004

Thomas, J., and Harden, A. (2008). Methods for the Thematic Synthesis of Qualitative Research in Systematic Reviews. BMC Med. Res. Methodol. 8 (1), 45. doi:10.1186/1471-2288-8-45

Tomazin, F. (2020). Fears of Blood Shortages as Donations Drop during Coronavirus. The Sydney Morning Herald, 2020.

Tran, N. Y. L., Charbonneau, J., and Valderrama-Benitez, V. (2013). Blood Donation Practices, Motivations and Beliefs in Montreal's Black Communities: the Modern Gift under a New Light. Ethn. Health 18 (6), 508-529. doi:10.1080/13557858.2012.734279

Tran, S., Lewalski, E. A., Dwyre, D. M., Hagar, Y., Beckett, L., Janatpour, K. A., et al. (2010). Does Donating Blood for the First Time during a National Emergency Create a Better Commitment to Donating Again. Vox Sang 98 (3 Pt 1), e219-24. doi:10.1111/j.1423-0410.2009.01274.x

Udow-Phillips, M., and Lantz, P. M. (2020). Trust in Public Health Is Essential amid the COVID-19 Pandemic. J. Hosp. Med. 15, 431-433. doi:10.12788/ jhm. 3474

Wittock, N., De Krom, M. P. M. M., and Hustinx, L. (2019). Blood's OntologiesEntangled: Qualitative Inquiry into the Enactment, Representation, and Organizational Modes of Coordination of Blood's Multiplicity in a Belgian Blood Establishment. Organization 26 (4), 470-491. doi:10.1177/ 1350508418808234

Wynne Busby, H. (2010). Trust, Nostalgia and Narrative Accounts of Blood Banking in England in the 21st century. Health (London) 14 (4), 369-382. doi:10.1177/1363459309359717

Yardley, L. (2000). Dilemmas in Qualitative Health Research. Psychol. Health 15 (2), 215-228. doi:10.1080/08870440008400302

Conflict of Interest: The authors declare that the research was conducted in the absence of any commercial or financial relationships that could be construed as a potential conflict of interest.

Publisher's Note: All claims expressed in this article are solely those of the authors and do not necessarily represent those of their affiliated organizations, or those of the publisher, the editors, and the reviewers. Any product that may be evaluated in this article, or claim that may be made by its manufacturer, is not guaranteed or endorsed by the publisher.

Copyright (c) 2022 Haw, Thorpe and Holloway. This is an open-access article distributed under the terms of the Creative Commons Attribution License (CC $B Y$ ). The use, distribution or reproduction in other forums is permitted, provided the original author(s) and the copyright owner(s) are credited and that the original publication in this journal is cited, in accordance with accepted academic practice. No use, distribution or reproduction is permitted which does not comply with these terms. 